\title{
The evaluation of the investment environment in the industrial activity in Jordan
}

\author{
Mohammed Al-Shoura ${ }^{1}$ and Anas Al Bakri' ${ }^{2 *}$ \\ ${ }^{1}$ School of Management, Faculty of Business, Middle East University (MEU), Jordan. \\ ${ }^{2}$ Management and Marketing Department, Faculty of Business and Economics, Qatar University, Al Tarfa, \\ Doha 2713, Qatar.
}

Accepted 15 April, 2013

\begin{abstract}
The aim of this paper is to evaluate the investment environment in Jordan from the perceptions of the workers in the industrial activity. Data was collected by a questionnaire which depended on five aspects; namely; economic infrastructure, the characteristics of the Jordanian economic environment, labor force, industrial free zones and the Jordan Investment Board and the promotion policies. 70 questionnaires were distributed to the workers of the Jordanian industrial activity out of 120 workers which represent the study sample. 40 questionnaires were valid to statistical analysis, which is equivalent to $57.1 \%$ of the study sample. The study used SPSS for analyzing data to estimate the averages, standard deviations, T-test, percentages and frequencies. Statistical analysis showed that the characteristics of the economic infrastructure, the economic investment environment, and the industrial free zones have positive impact on attracting foreign investments. The study highly recommends that in order to improve water supply service, there is a need for greater exploitation of ground water, expanding of current dams and maintaining water piping networks. Another recommendation is reviewing the investment legislation so as to modify the investment encouragement laws which includes a guarantee for more incentives for foreign investments.
\end{abstract}

Key words: Foreign investments, investment environment, economic infrastructure.

\section{INTRODUCTION}

The third world countries have been recently competing to pave the way for attracting foreign investments in order to realize the economic development. The encouragement of such investment is related to several factor; providing a stable economic and political environment, a convenient infrastructure, freedom of trade competition, and the guarantee of investment protection. Furthermore, it is essential to provide man power, natural resources and rules that guarantee the intellectual property, invention rights and motives for investors. Jordan is a third world country that has very limited potentials. In the late eighties, Jordan faced many economic crises because of the retreat of external aids and the decrease of the money transferred by Jordanians abroad. Furthermore, the exports market of Jordanian products and the demand on Jordanian man power declined. Other reasons of these crises include the deficiency in the Jordanian balance of payment and the general budget, the retreat of gold reserves and foreign currency, the retreat of economic growth, the increase of unemployment, the decline of Jordan Dinar exchange, the increase of inflation and the degradation of the standards of living relative to the individual portion of the gross domestic product (Economic and Social Commission for Western 
Asia (ESCAWA, 2003). As a result, Jordan has adapted many economic reform programs to insure a stable and an attracting environment for local and foreign investments. Jordan has also invested through many development projects and it has also depended on new legislations that provide motives and exemptions for foreign and local environments.

\section{The significance and importance of the study}

This study sheds some light on the investment environment in Jordan, the Jordan Investment Board and Investment Motives. It also provides a diagnosis of the advantages and disadvantages of the Jordanian investment environment.

Despite the great efforts done to attract more foreign and local investments, it investment is still limited compare to other countries. Therefore, this study aims at evaluating the investment situation in Jordan from the point of view of the personnel in the Jordan Investment Board and the Jordanian industrial estates. As a result, the obstacles that stop the flow of investments to Jordan will be clarified through the study. The problem of this study can be summarized by asking the following questions:

1. Do the characteristics of the economic environment in Jordan motivate the foreign investment to be directed toward Jordan?

2. Do the number and qualifications of labor force in Jordan contribute in directing foreign investments toward Jordan?

3. Do the industrial estates and free zones play a significant role in directing foreign investments to Jordan?

4. Do the policies of promotion in Jordan and the Jordan Investment Board play an important role in attracting foreign investments?

5. Does the infrastructure of Jordan economy contribute in attracting foreign investments?

\section{The objectives of the study}

The main objective is to clarify the point of view of the personnel towards the situation of investment environment in Jordan through:

1. The characteristics of the Jordanian economic environment and its role in attracting foreign investment.

2. The role of the labor force in Jordan in directing foreign investments toward Jordan.

3. The role of the industrial estates and free zones in attracting foreign investments to Jordan.

4. The role of the policies of promotion in Jordan and the Jordan Investment Board in attracting foreign investments.
5. The characteristics of infrastructure of Jordan economy and its role in attracting foreign investments.

6 . Some suggestions are presented so as to improve the investment environment in Jordan.

\section{Hypothesis of the study}

The First hypothesis: The characteristics of the economic environment in Jordan do not motivate the foreign investment to be directed toward Jordan.

The second hypothesis: the labor force in Jordan does not contribute in directing foreign investments toward Jordan.

The third hypothesis: The industrial estates and free zones do not play a significant role in directing foreign investments to Jordan.

The fourth hypothesis: The policies of promotion in Jordan and the Jordan Investment Board do not play an important role in attracting foreign investments.

The fifth hypothesis: The infrastructure of Jordan economy does not contribute in attracting foreign investments.

\section{The study population}

The study population includes the high and media personnel in the Jordan Investment Board and industrial estates, who have a direct relationship with foreign investments. They are estimated by 120 personnel.

\section{The study sample}

The equation used to decide the size of the study sample is given as follows (Geller and Brian, 2003):

$$
n=Z_{(a / 2)}^{2} /\left\{4 E^{2}+\left[Z_{(a / 2)}^{2} / N\right]\right\}
$$

Where: $\mathrm{n}$ is the size of sample, $\mathrm{E}$ is an accepted error, $\mathrm{Z}$ is the normal distribution, and $\mathrm{N}$ is the statistical population. Error is assumed to be in the range of 5 to $10 \%$ (average error $=7.5 \%$ ). Depending on this estimated error, the number of personnel in the study sample is 56 which represent $45 \%$ of the study population. Consequently, the stratified random sample is used where seventy questionnaires were distributed to 70 personnel in the Jordan Investment Board and industrial estates which represent $58 \%$ of the study population. Fifty questionnaires were restored which represent $71 \%$ of the distributed questionnaires. After revision, 10 questionnaires were excluded due to their invalidity for analysis. Therefore, 40 questionnaires were considered for analysis. 
Table 1. Description of the study sample (The personnel's demography).

\begin{tabular}{llcc}
\hline Variable & Interval & Frequency & Percentage \\
\hline \multirow{2}{*}{ Gender } & Male & 27 & 67.5 \\
& Female & 13 & 32.5 \\
& & & \\
Age & $\leq 30$ years & 13 & 32.5 \\
& $31-40$ years & 16 & 40.0 \\
& $41-50$ years & 9 & 22.5 \\
& $\geq 50$ & 2 & 5.0 \\
Qualification & & 2 & \\
& High school or less & 1 & 0 \\
& Diploma & 20 & 50.5 \\
& Bachelor & 17 & 42.5 \\
& Graduates studies & & \\
& & 10 & 25.0 \\
& $<5$ years & 11 & 27.5 \\
Experience & 5-10 years & 9 & 22.5 \\
& $11-15$ years & 10 & 25.0 \\
& $\geq 16$ years & 40 & 100.0 \\
\hline & Total & &
\end{tabular}

Table 2. The rating level according to Likert scale.

\begin{tabular}{ll}
\hline The average & The rating level \\
\hline 4.5 - 5 & Very high \\
3.75 - less than 4.5 & High \\
3 - less than 3.75 & Medium \\
2 - less than 3 & Weak \\
1 - less than 2 & Very weak \\
\hline
\end{tabular}

\section{DATA COLLECTION}

\section{Secondary data}

It is the statistical data which are collected from the official directorates and institutions which are concerned about local and foreign investments. The economic and financial brochures of the Central Bank of Jordan (2011, 2012) are an example.

\section{Primary data}

They were collected by using the following method. First, the demographic data of the personnel such as gender, age, educational level, social status and experience (Table 1).

Second, the characteristics of economic environment are given in Table 5. Third, the characteristics of labor force in Jordan are given in Table 7. Fourth, the characteristics of the industrial estates and free zones are given in Table 9. Fifth, the Jordan Investment Board and promotion polices are given in Table 11. Sixth, the economic infrastructure is given in Table 13. Likert penta scale was used as follows: $(1=$ strongly agree, $2=$ agree, 3 = don't know, 4 = disagree, 5 = strongly disagree). Table 2 explains the rating level for results depending on Likert scale:

\section{Validity and stability of the method}

Three foreign investment referees evaluated the questionnaires and consequently some modifications were done in the light of their notes. In order to prove the stability of the method, the measure of internal consistency (Cronbach-alpha method) was used. The index validity was used for the whole aspects of the method and the study by calculating of squares of coefficients of the whole method when it is applied on a preliminary sample study (out of the study sample), which consists of 12 investors. The coefficient of internal consistency was calculated to be 0.92 according to Cronbach-alpha equation. Table 3 gives the coefficients of internal consistency according to Cronbach-alpha equation for the five aspects of the study.

\section{The statistical methods used in the study}

In order to describe the characteristics of the sample, the SPSS program was used to analyze the data to find the frequencies and the percentages. Furthermore, the 
Table 3. Coefficients of internal consistency according to Cronbach's-alpha equation for the aspects of the study.

\begin{tabular}{lc}
\hline Aspects & $\begin{array}{c}\text { Internal } \\
\text { consistency }\end{array}$ \\
\hline The economic infrastructure & 0.78 \\
The economic environment & 0.74 \\
Labor force & 0.82 \\
Free zones and industrial estates & 0.77 \\
The Jordan Investment Board and & 0.80 \\
promotion & \\
\hline
\end{tabular}

average and the standard deviation were used to measure the degree of evaluation of the items of questionnaire. T-test was used to test the hypothesis of study.

\section{LITERATURE REVIEW}

Many studies discussed the factors that influence the flow of investments. Most important studies were Hijazin study (1996), discussed the factors that impede the foreign investments in Jordan; the weakness and instability of the economic structure, the legal environment, the weakness of the Jordanian policy of promotion and the weakness of the Jordan Investment Board. However, the study explained that the factors of security and political stability, the social environment, the low wages of employees encourage foreign investment.

Gharaibah and Azzam's study (1997) entitled "The determinants of foreign investments in the Jordanian economy" aimed at analyzing the situation of the Jordanian economy so as to measure all the factors that motivate more foreign investments. The study also discussed the types and the natures of the foreign investments and the Jordanian investment environment. Furthermore, this study applied a standard model which found out that the national income and growth, the political stability, trade conditions and local exchange play an important role in attracting foreign investments. The study of Hassan (1997) aimed at estimating the gap of the growth of the Jordanian economy during the years 1996 to 2001. It also estimated the productivity of the foreign capital during the years 1973 to 1975 . This study also predicted the future and the need of the foreign capital in Jordan. Moreover, it considered the achievements of the second economic reform program during the years 1992 to 1996 . The study showed that the Jordanian economy would suffer from the domination of foreign trade gap (foreign exchange) during the years 1996 to 2001. This study stressed on the positive effects of the foreign capital on the growth of the Jordanian economy. So, this study came to the conclusion that the Jordanian economy needs more foreign capital flow to ensure more growth rate of the economy. In the study of Muheesen (1999), the role of foreign investment in Amman Stock Exchange was introduced due to the increase of the non Jordanian investors who participate in the capital of the general joint-stock companies. On the other hand, the study found the strong and direct relationship between the stock price and the non Jordanian investors' shares. This direct relationship is also clear between the shares of the non Jordanian investors and the foreign net balance in the banking system. The legislation of the new laws concerning Amman Stock Exchange and the freedom of capital transfers paved the way for more foreign investments in Amman Stock Exchange.

"The investment conditions in Jordan and Egypt" is the title of a study issued by the Jordan Investment Board in 2001. Thirty investors in Egypt mentioned many reasons that prevented them from the investment in Jordan. High rates of taxes, customs duties, complicated project license, complex customs procedures, lack of transparency, the long routine, the high cost finance and the unqualified employees are the major obstacles against investment in Jordan. In addition, the study of Abdusalam (2002) dealt with the situation of foreign investment in Egypt especially after applying the economic reform policy in 1991. The study concluded that many obstacles face the investment in Egypt, such as the weakness of promotion policy, the deficiency of the taxes, legislative and managing systems, and the shortage of the research and development by comparison with other countries. Furthermore, in their study, Gyapong and Karikari (1999) made a comparison between the economic system of Ivory Coast and Ghana. The study clarified how the Ivory Coast succeeded through its economic policies in attracting more foreign investment during the years 1960 to 1980 , compared with the economic policies of Ghana which did not motivate foreign investments to come to the country. On the other hand, the researchers Alvin and Densil (2002) discussed the efforts which were done by the developing countries to improve their economy to attract foreign investments. The researchers constructed a statistical model which was consisted of explanation elements on the flow of the foreign investment such as interest rate, the average of economic growth, the average of individual's income and the balance of payment. The study came to the conclusion that the average of the individual income and interest rate are the major factors of attracting foreign investments.

In another comparative study between Bahrain and North Ireland, Gilmore et al. (2003) investigated the motivations introduced and the degree of satisfaction of the foreign investments from the point of view of the general managers. They also explained the reasons that stand behind preferring a country for executing projects over other countries. Furthermore, the study mentioned that all projects in Bahrain are joint ones, while in Ireland they are not. Moreover, both countries shared the main 
factors which attract investments (to different degrees) such as taxes, infrastructure and political stability. However, low wages is not an obstacle against foreign investments. The study of Metwally (2004) analyzed the relationship between the foreign investments and the economic growth in Jordan, Egypt and Oman. Most foreign investments in these countries come from the European Union. The study also showed that the rate of the economic growth in these countries has a positive effect on the flow of the foreign investments to different degrees.

\section{THEORETICAL FRAMEWORK OF THE STUDY}

Investment is defined as the use of the capital to get profits. It is also defined as the concession of the current consumption to get future returns. On the other hand, it is economically defined as the appropriation of the capital to gain new productive methods and develop them to increase the production power.

All the previous definitions stress that the investment is considered as a total addition to the productive capital used in the production and services to gain more profits. However, we should pay more attention to the negative effects of the political economic and social factors on investment. The World Trade Organization (WTO, 1997) defines "the direct foreign investment" as the ownership of a production line in the host country by a foreign investor, which enables him to manage it and gain profits.

\section{The characteristics of foreign investments}

According to Geel (1982), foreign investment is characterized by:

(1) Long-term investment.

(2) The ownership of a total or a partial project by a foreign investor.

(3) The investor has a partial or a total domination on managing and organizing the projects financially and technologically.

(4) The possibility of transforming experiences from the mother country to the host country.

\section{The determinants of foreign investments}

\section{The economic factors}

The investors take into consideration the economic situation of the host country such as the local production, inflation, market volume, the natural and basic recourses, external trade, foreign exchange, trade balance, public debts, open economy and the role of the public and private sectors in the economy. All the previous factors are necessary for attracting foreign investments.

\section{The labor force}

Training and qualifying of human resources are important in increasing the ability of the country inorder to attract foreign investments. Furthermore, the success of any investment project, the realization of more profits and the adaptability with market needs cannot be fulfilled without the human resources.

\section{The infrastructure}

The decrease of transport, communications, electricity, water, education and health services are considered to be repulsive factors of foreign investments (Hijazin, 1996; Gharaibeh and Azzam, 1997).

\section{The investment promotion}

It is a set of activities that motivate the capable and interested businessmen as well as the investment corporations to participate in the projects of investment. This should happen with the cooperation of the corporations in the host country. The investment promotion is considered one of the integral elements of the investment environment and a connecting link of all the investment parties to provide them with the information they need and it also encourages more foreign and local investments. Some organizations such as the United Nations Investment Development Organization (UNIDO) carry out many investment promotion activities. Training courses for the personnel who are working in the investment aspects, the financial support for countries willing to establish centers for the investment promotion or improving current promotion methods are some of these activities.

\section{Some characteristics of the investment environment in Jordan}

In Jordan, many investment sectors have witnessed services and infrastructure improvements. Here are some examples of the improved sectors:

1. Communication services: The infrastructure of the wired and wireless communications sectors and the 
sector of the information technology have developed in Jordan during the last few years. 373 companies work in this sector which expects a growth in its products markets by $10 \%$ in the few coming years.

2. Water sector: Jordan is one of the ten countries which suffer a shortage of water. One third of water resources in Jordan are not regenerated. Moreover, the average of the individual consumption of water in Jordan is about $200 \mathrm{~m}^{3} /$ year whereas in Syria, for example, it reaches about $800 \mathrm{~m}^{3} /$ year ( 9 folds of individual consumption of water in Jordan). On the other hand, the annual world average of water consumption is about $7700 \mathrm{~m}^{3} /$ year, while in North America it reached about $110000 \mathrm{~m}^{3} /$ year. For these reasons, Jordan's consequent governments adapted the projects of constructing dams to collect rain water. However, the problem is still in existent.

3. Transport services: The land carriage has been notably developed and expanded into wide areas in Jordan during the last years. The Gulf of Aqaba, on the other hand, is the Jordan main port for sea carriage. It has also witnessed a development by building special pavements and providing them with appropriate transport equipments. This development has also included the air transport, represented by the Royal Airlines. Planes of the Royal Jordanian Airlines reach directly to 47 cities in Europe, Middle and Far East, North America and Africa. There are also 26 airlines companies and 3 airports.

4. Education and Health: Jordan has been highly concerned with providing the essential infrastructure for schools and high education institutes. The percentage of educated people in Jordan has risen to be $87 \%$ in 2005 . This is due to the compulsory education for the elementary and preparatory levels. On the other hand, the achievements of the health sectors include giving people the health services in public and private hospitals, clinics and health centers. The number of hospitals in Jordan is about 98, 42 among them are public hospitals.

5. The economic environment: In an attempt to deal with the economic crisis and to readjust economic structure, the Jordanian government adapted many economic reform programs with the corporation of the International Bank and International Monetary Fund (IMF) in the late eighties, precisely 1989. However, this cooperation was blocked because of the second Gulf war in 1990, which forced the government to adapt the second economic reform program to cover the years 1992 to 1998.

To give the private sector more opportunity and to adapt the third reform economic program which started in 1998 and ended in 2003 to fight poverty and unemployment, Jordan adapted the privatization program. However, this program didn't fulfill all its objectives. Consequently, the government adapted the fourth reform program for the years 2002 to 2004. The main objective was to offer a stable economic structure and to control inflation. This program encourages more foreign investments
(Economic and Social Commission for Western Asia, ESCAWA, 2003).

The Jordanian finance sector, which is flexible and able to adapt with the economic condition, has a major role in forming a stable economic environment. It is also considered one of the basic fundaments that create an attracting investment environment. The stock exchange is a connecting link between individuals, saving institutions and the production projects through issuing stocks. Thus, the stock exchange is considered one of the elements of investment environment. Amman Stock Exchange has been established to increase the national savings and guarantee the best use of it in a way that guarantees correct, easy and quick dealings.

The Jordanian external trade policy depending on the philosophy of free economy, the Jordanian external trade policy has been able to reinforce Jordan's economic and trade relations with the Arab countries through signing the Arab free trade zone agreement and other dual free trade agreements. Jordan has also joined the joint agreement with European Union and the free trade agreement with USA. Jordan is also a member of the World Trade Organization and it signed many free trade agreements with Singapore and IFTA countries. Jordan signed over 32 dual investment agreements in order to develop the investment environment in Jordan. In December 1999, Jordan became the 135 member of the WTO. This membership facilitates penetration of the Jordanian products and services into the World markets (Economic and Social Commission for Western Asia, ESCAWA, 2003).

During the early nineties, Jordan started privatizing the public sector corporations gradually. This lead to the increase of the flow of foreign investment (ESCAWA, 2003). The Jordanian government sold all its portions in 64 companies. Cement Company, Communication Corporation, Public Transport Corporation, Arab Potash Company and Water Authority are examples of such companies. The gross yield of privatization reached more than one billion Jordan Dinar. The privatization program contributes to the attraction of foreign investments which exceeds one billion JD for privatized programs, especially the communication, water and transport sectors. In addition, Jordan suffers from a shortage in natural resources and the essential elements for growth such as petroleum and gas. However, Jordan is developed in the production of some minerals like phosphate, potash and manganese and other unexploited resources like oil shale and tar.

Table 4 shows the following: The amount of foreign investment was 438 million Dinar in the year 2004. Then in 2007 it decreased and kept on decreasing till it reached the lowest value (83.714) million Dinar in 2007. Then it raised in 2011 and 2012 due to the new laws and legislations which encourage the foreign investment (The annual report of the Jordan Investment Board, 2011, 
Table 4. Investment in Jordan (2000-2012).

\begin{tabular}{ccc}
\hline Year & $\begin{array}{c}\text { Foreign investment } \\
\text { /Dinar million }\end{array}$ & $\begin{array}{c}\text { Local investment } \\
\text { /Dinar million }\end{array}$ \\
\hline 2000 & 75.7 & 271.8 \\
2001 & 124 & 257.1 \\
2002 & 154.8 & 326.8 \\
2003 & 184.1 & 364.6 \\
2004 & 438.3 & 354.8 \\
2005 & 409.1 & 472.2 \\
2006 & 131.3 & 169.6 \\
2007 & 83.7 & 177.9 \\
2008 & 95.6 & 322.6 \\
2009 & 267.2 & 473.6 \\
2010 & 266.5 & 468.3 \\
2011 & 320 & 422.4 \\
2012 & 276.9 & 388.9 \\
\hline
\end{tabular}

Resource: Jordan Investment Board (2012).

2012). The local investment raised from 354.895 million Dinar in 2004 to 473.694 million Dinar in 2009.

\section{STATISTICAL ANALYSIS AND TEST OF HYPOTHESIS}

\section{First hypothesis}

The Jordanian economic environment does not attract foreign investments in Jordan. The first hypothesis was expressed in 13 items in Table 5 which refers to positive evaluation of the Jordanian economic environment. The evaluation of these items was higher than the degree of neutrality (3) which represents the average of five level scale used in the present study. Table 5 gives the values of average and standard deviation for the opinions of personnel in the Jordan investment boards, the industrial estates and the free trade zones about the suitability of Jordanian economic environment for the attraction of foreign investments. In order to prove or disprove the first hypothesis test $T$ was used at significance level 0.05 . It is clear from Table 6 that the general average of items of Table 5 equals 3.76 and that the value of T equals -3.481 and statistical significance level equals 0.001 . This confirms negation of the null hypothesis and affirmation of the alternative hypothesis that the positive characteristics of Jordanian economic environment attract foreign investments in Jordan.

Personnel affirmed that the following factors have positive role in the attraction of foreign investments: the stability of exchange rate of Dinar, the availability of foreign currency, free economic policies, programs of economic reformation in Jordan, the efficiency of the banking system and the availability of insurance service.
On the other hand, the degree of satisfaction of personnel was moderate with privatization policies, rate of taxes and fees, and stock exchange. Personnel affirm that inflation levels have negative effect on foreign investments. Furthermore, the evaluation of the effect of the size of budget disability and external indebtedness was positive, so these factors have no bad effects on foreign investments. However, dissatisfaction of foreign investors with inflation levels is due to its high levels in latter time which leads to the increase of investment expenses. Table 5 indicates that the rating level of personnel answers according to Likert scale is high (-3.75 less than 4.5) for more than half of the answers. This is a further support of our analysis of the first hypothesis.

\section{Second hypothesis}

Jordanian man power does not attract foreign investments in Jordan. The second hypothesis was expressed in 6 items in Table 7 which refers to positive evaluation of Jordanian man power. The evaluation of these items was higher than the degree of neutrality (3) which represents the average of five level scale used in the present study. Table 7 gives the values of average and standard deviation for the opinions of personnel in Jordan investment boards, industrial estates and free trade zones about the role of number and quality of Jordanian man power in attraction of foreign investments. In order to prove or disprove the second hypothesis test $T$ was used at significance level 0.05 . It is clear from Table 8 that the general average of items of Table 6 equals 3.29 and that the value of $T$ equals -2.928 and statistical significance level equals 0.004 . This confirms the negation of the null hypothesis and the affirmation of the alternative hypothesis that the positive characteristics of Jordanian man power do attract foreign investments in Jordan.

The Jordanian man power is characterized by high scientific and technical levels which are suitable for foreign investments in Jordan. Furthermore, the system of working hours and vacations is acceptable for investors, and the legislations applied in Jordan guarantee the right of persons in the investment process. Table 7 indicates that the rating level of answers of personnel in Jordan investment boards, industrial estates and free trade zones according to Likert scale is medium (-3 less than 3.75) for most of the answers. This is a further support of our analysis of the second hypothesis.

\section{Third hypothesis}

Industrial estates and free trade zones do not attract foreign investments in Jordan. The third hypothesis was expressed in 6 items in Table 9 which refers to the positive evaluation of the role of industrial estates and 
Table 5. Personnel evaluation of Jordanian economic environment.

\begin{tabular}{|c|c|c|c|}
\hline Item & Average & SD & $\begin{array}{l}\text { Rating } \\
\text { level }\end{array}$ \\
\hline Free economic policies in Jordan provides suitable economic environment for investment. & 4.38 & 0.67 & High \\
\hline The availability of foreign currency and its exchange are attractive for investment. & 4.33 & 0.62 & High \\
\hline The attendance of Jordan to World Trade Organization is attractive for investment. & 4.32 & 0.62 & High \\
\hline Stability of exchange rate of Dinar stimulates investments. & 4.22 & 0.80 & High \\
\hline The Banking system in Jordan is effective in servicing investments. & 4.15 & 0.77 & High \\
\hline Programs of the economic reform improve Jordanian economic environment for investment. & 4.10 & 0.63 & High \\
\hline Privatization policies improve the Jordanian economic environment. & 3.78 & 0.97 & High \\
\hline Jordanian Stock Exchange is effective and respects the benefits of investors. & 3.78 & 0.92 & High \\
\hline The service of Jordanian insurance sector is suitable for investment. & 3.43 & 0.98 & Medium \\
\hline The current Jordanian external indebtedness hinders flow of investment into Jordan. & 3.23 & 0.92 & Medium \\
\hline Taxes and fees in Jordan stimulate the flow of investments into Jordan. & 3.23 & 1.33 & Medium \\
\hline The acceptable economic inflation levels in Jordan encourage the flow of investments into Jordan. & 3.18 & 0.96 & Medium \\
\hline The general budget disability in Jordan has negative effect on the flow of investments into Jordan. & 2.83 & 1.01 & weak \\
\hline
\end{tabular}

Table 6. The values of general average and T test of the items of the first hypothesis (Jordanian economic environment).

\begin{tabular}{lccccl}
\hline Aspect & Average & SD & Value of T & Significance level & Result \\
\hline Jordanian economic environment & 3.76 & 0.45 & -3.481 & ${ }^{*} 0.001$ & Negation of null hypothesis \\
\hline${ }^{*}$ at significance level of $\alpha=0.05$. & & & & &
\end{tabular}

Table 7. Personnel evaluation of Jordanian man power.

\begin{tabular}{|c|c|c|c|}
\hline Item & Average & SD & Rating level \\
\hline $\begin{array}{l}\text { Jordanian man power is characterized by high scientific level which is suitable for foreign } \\
\text { investments in Jordan. }\end{array}$ & 3.70 & 0.99 & Medium \\
\hline The system of working hours and vacations in Jordan is suitable for investments. & 3.30 & 1.22 & Medium \\
\hline Legislations applied in Jordan guarantee the right of both personnel and investors. & 3.30 & 1.02 & Medium \\
\hline The number of man power in Jordan is sufficient for investments. & 3.03 & 1.12 & Medium \\
\hline
\end{tabular}

free trade zones in providing attractive investment environment in Jordan. The evaluation of these items was higher than the degree of neutrality (3) which represents the average of five level scale used in the present study. Table 9 gives the values of average and standard deviation for the opinions of personnel in Jordan investment boards, industrial estates and free trade zones about the role of industrial estates and free trade zones in the attraction of foreign investments. In order to prove or disprove the third hypothesis test $T$ was used at significance level 0.05 . It is clear from Table 10 that the general average of items of Table 9 equals 4.09 and that the value of $T$ equals -2.008 and statistical significance level equals 0.048 . This confirms negation of the null hypothesis and affirmation of the alternative hypothesis that industrial estates and free trade zones attracts foreign investments in Jordan.

The evaluation of the role of industrial estates and free trade zones was positive. The credit of some of these as qualified industrial zones contributes to various investments in Jordan. Investments in these industrial zones provide a way for reaching external markets because they provide facilities for encouraging investment in Jordan, well qualified labors and high competing products for external markets. Table 9 indicates that the rating level of answers of personnel in Jordan investment boards, industrial estates and free trade zones according to Likert scale is high (-3.75 less than 4.5$)$. This is a further 
Table 8. The values of general average and T test of the items of the second hypothesis (Jordanian man power).

\begin{tabular}{lccccl}
\hline Aspect & Average & SD & Value of T & Significance level & Result \\
\hline Man power in Jordan & 3.29 & 0.85 & -2.928 & ${ }^{\star} 0.004$ & Negation of null hypothesis \\
\hline
\end{tabular}

*at significance level of $\alpha=0.05$.

Table 9. Personnel evaluation of industrial estates and free trade zones in Jordan.

\begin{tabular}{|c|c|c|c|}
\hline Item & Average & SD & Rating level \\
\hline $\begin{array}{l}\text { Investment in industrial estates and free trade zones in Jordan provides a way for } \\
\text { reaching external markets. }\end{array}$ & 4.30 & 0.56 & High \\
\hline Industrial estates and free trade zones in Jordan facilitate investment in Jordan. & 4.18 & 0.81 & High \\
\hline $\begin{array}{l}\text { The location of the industrial estates and free trade zones in Jordan is suitable for } \\
\text { investment. }\end{array}$ & 4.10 & 0.81 & High \\
\hline Well qualified personnel are available in industrial estates and free trade zones in Jordan & 4.00 & 0.88 & High \\
\hline $\begin{array}{l}\text { Products of industrial estates and free trade zones in Jordan have competitive quality in } \\
\text { external markets. }\end{array}$ & 4.00 & 0.78 & High \\
\hline $\begin{array}{l}\text { The credit of some industrial estates as qualified zones strengthens the position of } \\
\text { investments in Jordan. }\end{array}$ & 3.95 & 0.96 & High \\
\hline
\end{tabular}

Table 10. The values of general average and T test of the items of the third hypothesis (industrial estates and free trade zones in Jordan).

\begin{tabular}{lccccc}
\hline Aspect & Average & SD & Value of T & Significance level & Result \\
\hline Industrial estates and free trade zones in Jordan & 4.09 & 0.60 & -2.008 & \multirow{2}{*}{0.048} & $\begin{array}{l}\text { Negation of null } \\
\text { hypothesis }\end{array}$ \\
\hline
\end{tabular}

*at significance level of $\alpha=0.05$.

Table 11. Personnel evaluation of Jordan Investment Board and promotion policies.

\begin{tabular}{|c|c|c|c|}
\hline Item & Average & SD & Rating level \\
\hline Jordan Investment Board facilitates of investors dealings. & 4.30 & 0.76 & High \\
\hline Jordan Investment Board promotes investments opportunities in Jordan in external markets. & 4.13 & 0.82 & High \\
\hline $\begin{array}{l}\text { Jordan investment Board makes national and international exhibitions and promotion } \\
\text { programs for Jordanian products. }\end{array}$ & 3.90 & 1.01 & High \\
\hline $\begin{array}{l}\text { Jordan Investment Board has well qualified personnel to manage and carry out promotion } \\
\text { process. }\end{array}$ & 3.75 & 0.90 & High \\
\hline Jordan mass media contributes to the clarification of investments opportunities in Jordan. & 3.62 & 1.13 & medium \\
\hline
\end{tabular}

support of our analysis of the third hypothesis.

\section{Fourth hypothesis}

Jordan Investment Board and promotion policies do not attract foreign investments in Jordan. The fourth hypothesis was expressed in 6 items in Table 11 which refersto positive evaluation of role of Jordan Investment Board and promotion policies in providing attractive investment environment in Jordan. The evaluation of these items was higher than the degree of neutrality (3) which represents the average of five level scale used in the present study. Table 11 gives the values of average and standard deviation for the opinions of personnel in Jordan Investment Board, industrial estates and free 
Table 12. The values of general average and T test of the items of the fourth hypothesis (Jordan Investment Board and promotion policies).

\begin{tabular}{lccccl}
\hline Aspect & Average & SD & Value of T & Significance level & Result \\
\hline Jordan Investment Board and promotion policies & 3.94 & 0.71 & -3.004 & ${ }^{*} 0.004$ & $\begin{array}{l}\text { Negation of null } \\
\text { hypothesis }\end{array}$ \\
\hline
\end{tabular}

*at significance level of $\alpha=0.05$.

Table 13. Personnel evaluation of Jordanian Investment Board and promotion policies.

\begin{tabular}{lccl}
\hline Item & Average & SD & Rating level \\
\hline Communication service is available in Jordan. & 4.60 & 0.55 & Very high \\
Suitable education is available in Jordan. & 4.38 & 0.77 & High \\
Satisfactory health service is available in Jordan & 4.18 & 0.93 & High \\
Good hotels and restaurants are available in Jordan. & 4.10 & 0.96 & High \\
Air transport is available in Jordan. & 3.90 & 0.78 & High \\
Technical services are available in Jordan. & 3.83 & 0.87 & High \\
Suitable electricity service is available in Jordan. & 3.78 & 0.97 & High \\
Land carriage is available in Jordan. & 3.70 & 0.82 & Medium \\
Sea carriage is available in Jordan. & 3.60 & 0.96 & Medium \\
Satisfactory sanitary service is available in Jordan. & 3.58 & 1.11 & Medium \\
Water supply service is available in Jordan. & 2.40 & 1.26 & weak \\
\hline
\end{tabular}

Table 14. The values of general average and $T$ test of the items of the fourth hypothesis (Jordanian Investment Board and promotion policies).

\begin{tabular}{lccccl}
\hline Aspect & Average & SD & Value of T & Significance level & Result \\
\hline Jordanian economic infrastructure & 3.82 & 0.53 & -2.778 & ${ }^{*} 0.007$ & Negation of null hypothesis \\
\hline
\end{tabular}

*at significance level of $\alpha=0.05$.

trade zones about the role of Jordanian Investment Board and promotion policies in attraction of foreign investments. In order to prove or disprove the fourth hypothesis test $T$ was used at significance level 0.05 . It is clear from Table 12 that the general average of items of Table 11 equals 3.94 and that the value of $T$ equals 3.004 and statistical significance level equals 0.004 . This confirms negation of the null hypothesis and affirmation of the alternative hypothesis that Jordan Investment Board and promotion policies attract foreign investments in Jordan.

The evaluation of the role of Jordan Investment Board and promotion policies was positive. Jordan investment board facilitates investment dealings, provides accurate information for investors, and promotes investments (in Jordan) in external markets. Jordan Investment Board makes national and international exhibitions and promotion programs by well qualified personnel. Jordan mass media contributes to clarification of investments opportunities in Jordanian market. Table 11 indicates that the rating level of answers of personnel according to
Likert scale is high (-3.75 less than 4.5) for almost all answers. This is a further support of our analysis of the fourth hypothesis.

\section{Fifth hypothesis}

Jordanian economic infrastructure does not attract foreign investments in Jordan. The fifth hypothesis was expressed in 11 items in Table 13 which refers to positive evaluation of the role of Jordanian economic infrastructure (local and international communications, health service, land carriage, air transport, sea carriage, education, electricity and water supply). The evaluation of these items was higher than the degree of neutrality (3) which represents the average of five level scale used in the present study. Table 14 gives the values of average and standard deviation for the opinions of personnel in Jordan Investment Board, industrial estates and free trade zones about the role of Jordanian economic infrastructure in attraction of foreign investments. In order 
to prove or disprove the fourth hypothesis test $\mathrm{T}$ was used at significance level 0.05 . It is clear from Table 14 that the general average of 11 items of Table 13 equals 3.82 and that the value of $T$ equals -2.778 and statistical significance level equals 0.007 . This confirms negation of the null hypothesis and affirmation of the alternative hypothesis that Jordanian economic infrastructure attracts foreign investments in Jordan.

Personnel of the sample study express their opinions that the Jordanian economic infrastructure has many positive characteristics that encourage foreign investments to be involved in the Jordanian economic environment is ready to welcome investors as it is seen from Table 13 where the rating level of answers of personnel according to Likert scale is high (-3.75 less than 4.5) for almost all answers. This is a further support of our analysis of the fifth hypothesis.

\section{Conclusions}

(1) The characteristics of the economic environment in Jordan encourage the foreign investment to be directed to Jordan. Such characteristics include : the relative stability of Dinar exchange rate, suitable circulation of the foreign currency, open economic policies, the economic reform programs and the efficiency of the banking and insurance services.

(2) The educational and technical qualifications and the sufficient numbers of the man power in Jordan attract the foreign investment to Jordan. In addition to the acceptable system of the working hours and the vacations, the legislations guarantee the rights of all the parts of the economic operation.

(3) The Jordanian industrial estates and free zones play an important role in the encouragement of foreign investment. They participate in reinforcing the different kinds of investment by offering facilities to encourage investment in Jordan. These industrial estates and free zones have proper locations and high competitive abilities in the foreign markets.

(4) The Jordan Investment Board together with the promotion policy applied in Jordan play a role in attracting foreign investment by creating a comfortable and an attracting investment environment facilitating the deals of the investment. They also provide the investors with the accurate needed information. Furthermore, they promote for the opportunities of investment in Jordan through the local and international exhibitions executed by a qualified staff who manage the promotion process. The role of the Jordanian mass media in clarifying the investment aspects in the Jordanian markets cannot be denied.

(5) The characteristics of the economic infrastructure in Jordan have many advantages, which help in attracting foreign investment. For example, the services of the local and international communication, the health services, the air transport, land and sea carriage, education, water and electricity affect the economic infrastructure positively. These services help in attracting foreign investment.

\section{Recommendations}

Depending on the previous conclusions, some recommendations that may enhance the advantages of the Jordanian investment environment will be introduced.

(1) Improving water services through the exploitation of ground water in Disi Deposit, expanding dams and repairing water networks.

(2) Adapting financial and monetary policies that restrain the inflation and improving the economic environment especially through new legislations.

(3) Modifying the investment legislations by a team of public and private sectors, the thing that realize more foreign investment in the manufacturing of textiles, electronic products and the sector of information technology. Moreover, the foreign investor needs such as human resources and Arab experts should be satisfied without many complications.

(4) Establishing more vocational colleges and corporations and improving the working ones so as to provide investors with qualified human resources.

(5) Constructing specialized investment units in foreign countries and organizing a promotion campaign to promote for the Jordanian high quality products.

\section{REFERENCES}

Abdusalam M (2002). The situation of foreign investment in Egypt especially after applying the economic reform policy in 1991 .

Alvin GW, Densil AW (2002). "Attracting FDI to developing countries: A changing role for government?". Int.J.Public Sector Manag., 15(5): $361-374$.

Central Bank of Jordan (CBJ) (2012). Central bank Bulletin, Quarter Publish, Retrieved 15/July/2012, central bank website. Amman, Jordan.

Central Bank of Jordan (CBJ) (2011). Central bank Bulletin, Quarter Publish, Retrieved 15/July/2012, central bank website. Amman, Jordan.

Economic and Social Commission for Western Asia, ESCAWA (2003).

Geller G, Waarade B (2003). Statistic, 6 Edition, p.315.

Gharaibah H, Azzam A (1997). "The determinants of foreign investments in the Jordanian economy, Yarmouk J. 13(1):22-24, 3351.

Gilmore A, Aodheen D, Carson D, Cummins D (2003). Factors Influencing Foreign Direct Investment And International Joint Venture, International Marketing Review , Northern Ireland 20(2):195215.

Gyapong A, Karikari J (1999), Direct Foreign Investment Strategies And Economic Performance In Ghana And Ivory Coast, J. Econ. Dev. 24(1):133-147.

Hassan $\mathrm{H}$ (1997). "The gap of the growth of the Jordanian economy during the years 1996-2001", unpublished master thesis, Yarmouk University.

Hijazin A (1996). "The factors that impede the foreign investments in Jordan; the weakness and instability of the economic structure, the 
legal environment", unpublished master thesis, the University of Jordan.

Metwally A (2004). Analyzed the relationship between the foreign investments and the economic growth in Jordan, Egypt and Oman.

Muheesen $F$ (1999). The role of foreign investment in Amman Stock Exchange, Bank. J. 18(8):49-55.

The annual report of the Jordan Investment Board (2011). AmmanJordan, unpublished statistics Jordan Investment Board.

The annual report of the Jordan Investment Board (2012). AmmanJordan, unpublished statistics Jordan Investment Board.
The Jordan Investment Board (2001) "The investment conditions in Jordan and Egypt". Retrieved 10/July/2012.

World Trade Organization (WTO) report (1997). Trade and foreign direct investment, USIA Electronic J. 2(2). 